Jurnal Matematika UNAND

Vol. VIII No. 2 Hal. 135 - 140

Edisi Agustus 2019

ISSN : 2303-291X

(C)Jurusan Matematika FMIPA UNAND

\title{
SIFAT-SIFAT ALJABAR LIE
}

\author{
SA'DHA DWI MEITIA, NOVA NOLIZA BAKAR, YANITA \\ Program Studi S1 Matematika, \\ Fakultas Matematika dan Ilmu Pengetahuan Alam, Universitas Andalas, \\ Kampus UNAND Limau Manis Padang, Indonesia. \\ email : sadhadm@gmail.com
}

Diterima 22 Juni 2019 Direvisi 6 Juli 2019 Dipublikasikan 4 Agustus 2019

\begin{abstract}
Abstrak. Suatu himpunan tak kosong $R$ yang memenuhi aksioma tertentu, ada yang dikatakan grup dan ada yang dikatakan ruang vektor. Suatu aljabar Lie $L$ adalah ruang vektor atas lapangan $F$ dengan perkalian [, ] yang disebut Bracket Lie dan memenuhi beberapa aksioma tertentu. Pada artikel ini akan dikaji bagaimana sifat-sifat yang terkait dengan aljabar Lie, seperti sub-aljabar, komutatif dan ideal.
\end{abstract}

Kata Kunci: Aljabar Lie, Sub-aljabar Lie, Ideal

\section{Pendahuluan}

Suatu himpunan tak kosong $R$ yang memenuhi aksioma tertentu ada yang dikatakan grup dan ada yang dikatakan ruang vektor. Suatu ruang vektor atas lapangan F yang dilengkapi pemetaan yaitu Bracket Lie dan memenuhi beberapa aksioma tertentu, disebut sebagai Aljabar Lie. Misalkan diberikan suatu himpunan yang memenuhi kriteria aljabar Lie. Pada artikel ini akan dikaji bagaimana sifat-sifat yang terkait dengan aljabar Lie, seperti sub-aljabar, komutatif dan ideal.

\section{Landasan Teori}

Definisi 2.1. [10] Misalkan $A$ dan $B$ adalah suatu himpunan. Himpunan $A$ dikatakan himpunan bagian (subset) dari $B$, jika untuk setiap elemen dari $A$ merupakan elemen dari $B$. Simbol $A \subset B$ atau $B \supset A$ menunjukkan bahwa $A$ merupakan himpunan bagian dari $B$.

Definisi 2.2. [6] Suatu pemetaan $\phi$ dari himpunan $A$ ke himpunan $B$ adalah suatu aturan yang menghubungkan setiap $a \in A$ dengan tepat satu $b \in B$. Himpunan $A$ disebut daerah asal dari $\phi$, dan $B$ disebut daerah hasil dari $\phi$.

Definisi 2.3. [6] Misal G suatu himpunan. Operasi biner di G adalah pemetaan yang menghubungkan setiap pasangan berurut elemen di $G$ dengan suatu elemen di G.

Suatu himpunan $\mathrm{G}$ dengan operasi biner $*$ ditulis $(G, *)$. 
Definisi 2.4. [7] Elemen dari suatu himpunan tak kosong G dikatakan membentuk suatu grup jika pada $G$ dapat didefinisikan suatu operasi biner * sedemikian sehingga:

(1) $a, b \in G$ mengakibatkan $a * b \in G$ (Tertutup).

(2) $a, b, c \in G$ mengakibatkan $a *(b * c)=(a * b) * c$ (Hukum Asosiatif).

(3) Terdapat suatu unsur $e \in G$, sedemikian sehingga $a * e=e * a=a$ untuk setiap $a \in G$.

(4) Untuk setiap $a \in G$, terdapat suatu unsur $a^{-1} \in G$ sehingga berlaku $a * a^{-1}=$ $a^{-1} * a=e$ (terdapat invers di $G$ ).

Grup $G$ dengan operasi biner $*$ ditulis $(G, *)$

Definisi 2.5. [7] Suatu himpunan tak kosong $R$ dikatakan menjadi suatu ring asosiatif jika di $R$ terdefinisi dua operasi, yang masing-masingnya dinotasikan dengan $\oplus$ dan $\otimes$, sedemikian sehingga untuk setiap $a, b, c \in R$ :

(1) $a \oplus b d i R$.

(2) $a \oplus b=b \oplus a$.

(3) $(a \oplus b) \oplus c=a \oplus(b \oplus c)$.

(4) Terdapat elemen 0 di $R$ sedemikian sehingga $a \oplus 0=a$ (untuk setiap a di $R$ ).

(5) Terdapat elemen $-a$ di $R$ sedemikian sehingga $a \oplus(-a)=0$.

(6) $a \otimes b d i R$.

(7) $(a \otimes b) \otimes c=a \otimes(b \otimes c)$.

(8) $a \otimes(b \oplus c)=(a \otimes b)+(a \otimes c)$ dan $(b \oplus c) \otimes a=(b \otimes a) \oplus(c \otimes a)$ (Dua Hukum Distributif).

Jika perkalian pada $R$ mengakibatkan $a \otimes b=b \otimes a$ untuk setiap $a, b$ di $R$, maka $R$ disebut ring komutatif. [7]

Definisi 2.6. [7] Suatu ring $R$ dikatakan ring pembagi jika elemen bukan nol di $R$ membentuk grup dibawah operasi perkalian.

Definisi 2.7. [7] Suatu lapangan adalah ring pembagi yang komutatif.

Definisi 2.8. [9] Suatu ruang vektor $V$ atas lapangan $F$ adalah suatu himpunan $V$, dimana elemen dari $V$ disebut vektor, terdapat elemen $\overrightarrow{0}$ disebut vektor nol, bersama dengan operasi biner + , dikatakan penjumlahan vektor, dan suatu perkalian skalar dari elemen vektor di F yang memenuhi kondisi berikut:

(1) Untuk setiap $u, v, w \in V$ berlaku

- $u+v \in V$.

- $\overrightarrow{0}+v=v$.

- $u+v=v+u$.

- $u+(v+w)=(u+v)+w$.

(2) Untuk setiap $u, v \in V$ dan untuk setiap $r, s \in F$ berlaku

- $r v \in V$.

- $1 v=v$.

- $0 v=\overrightarrow{0}$. 
- $r(u+v)=r u+r v$.

- $(r+s) v=r v+s v$.

- $(r s) v=r(s v)$.

Definisi 2.9. [9] Suatu subruang dari ruang vektor $V$ adalah himpunan bagian $U$ $\subseteq V$ dimana $U$ adalah ruang vektor yang menggunakan operasi biner penjumlahan dan perkalian skalar yang sama seperti pada $V$.

Definisi 2.10. [9] Misal $U$ dan $V$ adalah ruang vektor atas lapangan $F$. Suatu transformasi linier $U$ ke $V$ adalah pemetaan $T: U \mapsto V$ dimana

(1) $\forall x, y \in V, T(x+y)=T(x)+T(y)$.

(2) $\forall x \in V, k \in F, T(k x)=k T(x)$.

Definisi 2.11. [9] Misal $T: U \rightarrow V$ adalah suatu transformasi linier, maka

(1) $\operatorname{Ker}(T)=\{u \in U \mid T(u)=\overrightarrow{0}\}$.

(2) $\operatorname{Im}(T)=\{T(u) \mid u \in U\}$.

\section{Pembahasan}

Definisi 3.1. [11] Suatu aljabar Lie L adalah ruang vektor atas lapangan F dengan perkalian [, ] yang disebut Bracket Lie yang didefinisikan dengan sifat sebagai berikut :

(1) Tertutup: Untuk $x, y \in L$ maka $[x, y] \in L$.

(2) Biliniar: $[x, \alpha y+\beta z]=\alpha[x, y]+\beta[x, z], \forall \alpha, \beta \in F$ dan $x, y, z \in L$.

(3) Antisimetri: $[x, y]=-[y, x]$.

(4) Identitas Jacobi: $[x,[y, z]]+[y,[z, x]]+[z,[x, y]]=0$.

Definisi 3.2. [3] Suatu aljabar Lie L dikatakan komutatif jika $\forall x, y \in L,[x, y]=0$.

Definisi 3.3. [5] Misal L suatu Aljabar Lie. Didefinisikan K sub-aljabar Lie dari $L$ jika $K$ subruang dari $L$ sedemikian sehingga

$$
[x, y] \in K, \forall x, y \in K .
$$

Definisi 3.4. [5] Misal L suatu Aljabar Lie. Suatu subruang I di L adalah suatu ideal di L jika

$$
[x, y] \in I, \forall x \in L, y \in I .
$$

Lema 3.5. [5] Misal I adalah suatu ideal di aljabar Lie L. I adalah suatu sub-aljabar Lie di L.

Bukti. Misal $I$ adalah suatu ideal di $L$. akan ditunjukkan $I$ adalah sub-aljabar Lie di $L$, yakni:

(1) $I \subset L$ dan $I \neq \emptyset$.

(2) $[x, y] \in I, \forall x, y \in I$. 
Perhatikan bahwa:

(1) Karena $I$ adalah ideal di $L$, maka jelas bahwa $I \subset L$ dan $I \neq \emptyset$.

(2) Misal $x, y \in I$. Oleh karena $I$ ideal di $L$, sedemikian sehingga $I \subset L$ maka $\forall x \in I, x \in L$. Selanjutnya karena $I$ ideal di $L$, maka $\forall x \in L, y \in I$, berlaku $[x, y] \in I$.

Lema 3.6. [5] Misal I dan J adalah suatu ideal di aljabar Lie L. Irisan I $\cap J$ adalah suatu ideal di $L$.

Bukti. Misal $I$ dan $J$ adalah ideal di $L$. Akan ditunjukkan $I \cap J$ adalah ideal di L, yakni

(1) $I \cap J \subset L$ dan $I \cap J \neq \emptyset$.

(2) $[x, y] \in I \cap J, \forall x \in L, y \in I \cap J$.

Perhatikan bahwa:

(1) Misal $x \in I \cap J$, berarti $x \in I$ dan $x \in J$. Oleh karena $I$ dan $J$ ideal di $L$, berlaku $I \subset L$ dan $J \subset L$, sehingga $x \in L$. Jadi $\forall x \in I \cap J, x \in L$, sehingga $I \cap J \subset L$. Selanjutnya karena $I$ dan $J$ ideal di $L$, maka $I$ dan $J$ adalah suatu subruang dari $L$. Akibatnya terdapat $\overrightarrow{0} \in I$ dan $\overrightarrow{0} \in J$, sehingga $\overrightarrow{0} \in I \cap J$. Jadi $I \cap J \neq \emptyset$

(2) Misal $x \in L$ dan $y \in I \cap J$. Akan ditunjukkan $[x, y] \in I \cap J$. Perhatikan bahwa $y \in I \cap J$, diperoleh $y \in I$ dan $y \in J$. Oleh karena $I$ dan $J$ ideal di $L$ maka $\forall x \in L, y \in I$, berlaku $[x, y] \in I$. Demikian juga $\forall x \in L, y \in J$, berlaku $[x, y] \in J$. Jadi $[x, y] \in I \cap J$.

Lema 3.7. [5] Misal I dan J adalah suatu ideal di aljabar Lie L. I+J adalah ideal di L dimana

$$
I+J=\{x+y, x \in I, y \in J\} .
$$

Bukti. Misal $I$ dan $J$ adalah ideal di $L$. Akan ditunjukkan $I+J$ adalah ideal di $L$, yakni

(1) $I+J \subset L$ dan $I+J \neq \emptyset$.

(2) $[x, y] \in I+J, \forall x \in L, y \in I+J$.

Perhatikan bahwa:

(1) Misal $x+y \in I+J$, dimana $x \in I$ dan $y \in J$. Karena $I$ dan $J$ ideal di $L$, berlaku $I \subset L$ dan $J \subset L$, sehingga $x, y \in L$. Jadi $\forall x, y \in L$, berlaku $x+y \in L$, sehingga $I+J \subset L$. Selanjutnya karena $I$ dan $J$ ideal di $L$, maka $I$ dan $J$ adalah suatu subruang dari $L$. Akibatnya terdapat $\overrightarrow{0} \in I$ dan $\overrightarrow{0} \in J$, sehingga $\overrightarrow{0} \in I+J$. Jadi $I+J \neq \emptyset$.

(2) Misal $x \in L$ dan $y \in I+J$ dimana $y=y_{1}+y_{2}$ untuk $y_{1} \in I$ dan $y_{2} \in J$. Oleh karena $I$ dan $J$ ideal di $L$, maka untuk $x \in L$ dan $y_{1} \in I,\left[x, y_{1}\right] \in I$. Demikian juga untuk $x \in L$ dan $y_{2} \in J,\left[x, y_{2}\right] \in J$. Jadi $[x, y]=\left[x, y_{1}+y_{2}\right]=$ $\left[x, y_{1}\right]+\left[x, y_{2}\right]$, sehingga $[x, y] \in I+J$. 
Definisi 3.8. [8] Misal L dan L' adalah suatu aljabar Lie. Suatu transformasi linier $\phi: L \mapsto L^{\prime}$ dikatakan homomorfisma jika $\phi([x, y])=[\phi(x), \phi(y)], \forall x, y \in L$.

Lema 3.9. [5] Misal L dan $L$ ' adalah suatu aljabar Lie atas lapangan $F$. $\operatorname{Ker}(\phi)$ dari pemetaan homomorfisma $\phi: L \rightarrow L^{\prime}$ adalah ideal bagi $L$ dan $\operatorname{Im}(\phi)$ dari pemetaan homomorfisma $\phi: L \rightarrow L^{\prime}$ adalah sub-aljabar Lie bagi $L^{\prime}$.

Bukti. Misal $L$ dan $L^{\prime}$ adalah suatu aljabar Lie atas lapangan $F$ dan $\phi$ adalah suatu pemetaan homomorfisma $L \rightarrow L^{\prime}$. Akan ditunjukkan

(1) $\operatorname{Ker}(\phi)$ adalah ideal bagi $L$, yakni

(a) $\operatorname{Ker}(\phi) \subset L$ dan $\operatorname{Ker}(\phi) \neq \emptyset$.

(b) $[x, y] \in \operatorname{Ker}(\phi), \forall x \in L, y \in \operatorname{Ker}(\phi)$.

(2) $\operatorname{Im}(\phi)$ adalah sub-aljabar Lie bagi $L$, yakni

(a) $\operatorname{Im}(\phi) \subset L^{\prime}$ dan $\operatorname{Im}(\phi) \neq \emptyset$.

(b) $\left[x^{\prime}, y^{\prime}\right] \in \operatorname{Im}(\phi), \forall x^{\prime}, y^{\prime} \in \operatorname{Im}(\phi)$.

Perhatikan bahwa:

(1) $\operatorname{Ker}(\phi)=\{x \in L \mid \phi(x)=0\}$.

(a) Oleh karena $\operatorname{Ker}(\phi)=\{x \in L \mid \phi(x)=0\}$, jelas bahwa $\operatorname{Ker}(\phi) \subset L$. Selanjutnya karena $L$ adalah suatu aljabar Lie, maka terdapat $\overrightarrow{0} \in L$ dimana $\phi(\overrightarrow{0})=0$. Jadi $\operatorname{Ker}(\phi) \neq \emptyset$.

(b) Misal $x \in L$ dan $y \in \operatorname{Ker}(\phi)$. Oleh karena $y \in \operatorname{Ker}(\phi)$, berarti $y \in L$ dan $\phi(y)=0$. Perhatikan bahwa karena $\phi$ homomorfisma,

$$
\begin{aligned}
\phi([x, y]) & =[\phi(x), \phi(y)] \\
& =[\phi(x), 0] \\
& =0
\end{aligned}
$$

Jadi karena $\phi([x, y])=0$, maka $[x, y] \in \operatorname{Ker}(\phi)$.

(2) $\operatorname{Im}(\phi)=\{\phi(x) \mid x \in L\}$.

(a) Oleh karena $\phi$ adalah pemetaan $L \mapsto L^{\prime}$, maka $\forall x \in L, \phi(x) \in L^{\prime}$. Jelas bahwa $\operatorname{Im}(\phi) \subset L^{\prime}$. Selanjutnya karena $L$ adalah suatu aljabar Lie, maka terdapat $\overrightarrow{0} \in L$, sehingga terdapat $\phi(\overrightarrow{0}) \in L^{\prime}$. Jadi $\operatorname{Im}(\phi) \neq \emptyset$.

(b) Misal $x^{\prime}, y^{\prime} \in \operatorname{Im}(\phi)$.

Karena $x^{\prime}, y^{\prime} \in \operatorname{Im}(\phi)$, maka terdapat $x, y \in L$, sehingga $\phi(x)=x^{\prime}$ dan $\phi(y)=y^{\prime}$. Perhatikan bahwa karena $\phi$ homomorfisma,

$$
\begin{aligned}
\phi([x, y]) & =[\phi(x), \phi(y)] \\
& =\left[x^{\prime}, y^{\prime}\right]
\end{aligned}
$$

Jadi karena $\phi([x, y])=\left[x^{\prime}, y^{\prime}\right]$, maka $\left[x^{\prime}, y^{\prime}\right] \in \operatorname{Im}(\phi)$. 


\section{Kesimpulan}

Aljabar Lie adalah suatu ruang vektor atas lapangan $\mathrm{F}$ dengan perkalian [, ] yang disebut Bracket Lie yang memenuhi beberapa aksioma tertentu. Dengan konsep yang hampir sama dengan ring, pada aljabar Lie juga memiliki ideal dimana ideal dari suatu aljabar Lie dapat dijadikan suatu sub-aljabar Lie dari aljabar Lie tersebut. Diberikan $I$ dan $J$ adalah ideal dari suatu aljabar Lie. Irisan $I \cap J$ adalah suatu ideal dari aljabar Lie tersebut dan penjumlahan $I+J$ dimana

$$
I+J=\{x+y \mid x \in I, y \in J\}
$$

juga adalah suatu ideal dari aljabar Lie tersebut.

Dari konsep pemetaan homomorfisma yang sama pada grup dan ring, pemetaan homomorfisma aljabar Lie, yakni $\phi: L \rightarrow L^{\prime}, \operatorname{Ker}(\phi)$ adalah suatu ideal dari aljabar Lie $L$ dan $\operatorname{Im}(\phi)$ adalah suatu sub-aljabar Lie dari aljabar Lie $L$ '.

\section{Daftar Pustaka}

[1] Anton, H. \& Rorres, C. 2010. Elementary Linear Algebra Applications Version, $10^{\text {th }}$ edition. Jhon Wiley and Sons, New York.

[2] Bartle, R. G. \& Sherbert, D. R., 2011. Introduction to Real Analysis. Jhon Wiley and Sons, New York.

[3] Bourbaki, Nicolas. 1975. Lie Groups and Lie Algebras. Hermann, France.

[4] Purcell, J.E. \& Varberg, D. 2006. Calculus with Differential Equation. Pearson, London.

[5] Erdmann, K \& Wildon, M. J. 2006. Introduction to Lie Algebras. Springer, New York.

[6] Gallian, J.A. 2013. Contemporary Abstract Algebra $8^{\text {th }}$ Edition. Brooks /Cole, USA.

[7] Herstein, I. N. 1975. Topics in Algebra, $2^{\text {nd }}$ Edition. Jhon Wiley and Sons, New York.

[8] Humphreys, J. E. 1980. Introduction to Lie Algebras and Representation Theory. Springer, New York.

[9] Jacob, B. 1990. Linier Algebra. W.H. Freetman and Company, USA.

[10] Setiawan, Adi. 2014. Dasar-Dasar Aljabar Modern: Teori Grup 83 Teori Ring. Tisara Grafika, Salatiga.

[11] Steeb, W. H. 2007. Continuous Symmetries, Lie Algebras, Differential Equations and Computer Algebra. World Scientific, USA. 